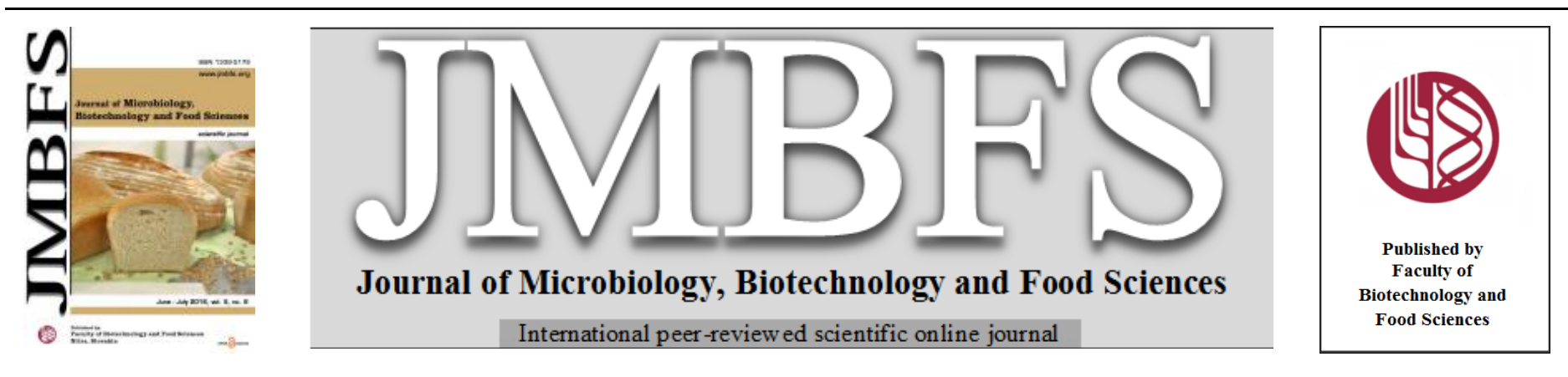

\title{
AGRO-INDUSTRIAL WASTE BASED GROWTH MEDIA OPTIMIZATION FOR BIOSURFACTANT PRODUCTION BY ANEURINIBACILLUS MIGULANUS
}

\author{
Mohamed Sellami ${ }^{l}$, Achref Khlifi ${ }^{l}$, Fakher Frikha ${ }^{l}$, Nabil Miled ${ }^{l}$, Lassad Belbahri ${ }^{2}$, Faouzi Ben Rebah ${ }^{3 *}$ \\ Address(es): Dr. Faouzi Ben Rebah, \\ ${ }^{1}$ Laboratoire de Biochimie et de Génie Enzymatique des Lipases, ENIS, Université de Sfax, Sfax-Tunisia. \\ ${ }^{2}$ Laboratory of Soil Biology, University of Neuchâtel, Neuchâtel, Switzerland. \\ ${ }^{3}$ King Khalid University, Community College at Khamis Mushait, PO Box 3926 - 61961, Saudi Arabia.
}

*Corresponding author: benrebahf@yahoo.fr

doi: 10.15414/jmbfs.2016.5.6.578-583

ARTICLE INFO

Received 10. 12. 2015

Revised 24. 1. 2016

Accepted 16. 2. 2016

Published 1. 6. 2016

Regular article

open $\partial_{\text {ACCESS }}$

\section{ABSTRACT}

The present work aimed to optimize a molasses and tuna-processing by-products based new economic medium for biosurfactant (BS) production by a promising strain of Aneurinibacillus migulanus. A culture medium based on a mixture of molasses and supernatants generated from tuna by-products supplemented with oligoelements solution was optimized using the mixture design methodology. Biosurfactant (BS) production and emulsification index (E24) were evaluated. Maximal BS of $2.95 \mathrm{~g} / \mathrm{l}$ was obtained with a $95: 5$ (v:v) mixture of molasses and tuna by-product supernatant. However, higher level of E24 (62\%) was recorded with medium containing the proportion 5:95 (v:v) of molasses and tuna by-product supernatant. The predicted responses from these mixture proportions were also validated experimentally. Interestingly, oligoelements supplements were not needed to prepare the culture medium. Molasses and tunaby-product, non-conventional substrates, can be used efficiently for BS production by A. migulanus.

Keywords: Biosurfactant, Aneurinibacillus migulanus, Emulsification index, Molasses, Tuna-by-product

\section{INTRODUCTION}

Surfactants are amphipathic molecules with hydrophilic and hydrophobic regions. These molecules can reduce surface tension at the air-water interface between two immiscible liquids or between the solid-water interfaces. They can adsorb at interface of the system and decrease interfacial free energy ( $\mathbf{Y u}$ and Huang, 2011). This characteristic confers excellent detergency, emulsifying, foaming and dispersing traits, making surfactant an interesting chemical for versatile process (Reis, et al., 2013). These components have applications in various industries such as petrochemical, oil, pharmacy, medical, cosmetics, food and pharmaceutics (Babu et al., 1996; Banat et al., 2010; Makkar and Cameotra, 2002; Muthusamy et al., 2008; Soberón-Chávez et al., 2011). In 2008, the annual global production of surfactants was 13 million metric tons and it is expected that the average annual growth of the global surfactant market will be $4.5 \%$ by 2018 , resulting in revenues of more than US\$ 41 billion (Ashby $\boldsymbol{e t}$ al., 2013). However, the currently used surfactants are generally chemically synthetic or derived from petroleum like alkylbenzene sulfonate, quaternary ammonium chloride, salt of long chain amine, sulfobetaine and polyoxyethylenated alkylphenol (Rosen and Kunjappu, 2012). These chemicals are often toxic and non-biodegradable, representing an additional source of contamination (Reis et al., 2013). For example, the introduction of surfactants into the soil environment, for the purposes of soil remediation, can lead to contamination concerns. Consequently, the toxicity of the surfactant and its potential degradation products needs to be carefully considered prior to its use (Van Hamme et al., 2006). In recent years, researchers are interested in microbial BS due to their diversity and their proprieties (lower toxicity, higher biodegradability, the ability to act in high temperatures, low $\mathrm{pH}$ and different salinity levels, higher foaming, etc.) (Reis, et al., 2013). BS have the ability to be synthesized by microorganisms with numerous potential applications in the environmental processing (crude oil recovery, heavy metal removal, etc.), in health care and in food-processing industries (Cameotra and Makkar, 2010). Consequently, BS are preferred to synthetic and chemical surfactants (DehghanNoudeh et al., 2009; Deleu and Paquot, 2004). Microbial BS are a structurally diverse group of surface active molecules including glycollipids, lipopeptides, phospholipids, fatty acids, neutral lipids, polymeric compounds, etc. (Reis et al., 2013). These molecules with hydrophobic and hydrophilic parts are either anionic, cationic or neutral. The hydrophobic part, which is less soluble in water, is based on long-chain fatty acids, hydroxy fatty acids or $\alpha$-alcyl $-\beta$ - hydroxy- fatty acids. The hydrophilic portion, which is more soluble in water, can be a carbohydrate, amino acid, cyclic peptide, phosphate, carboxylic acid or alcohol (Chayabutra et al., 2001; Chen et al., 2007; Volchenko et al., 2007). These molecules reduce surface and interfacial tensions in both aqueous solutions and hydrocarbon mixtures, which makes them potential candidates in various sectors as cited above such as the bioremediation processes (enhance oil recovery from wells, reduce the heavy oil viscosity, clean oil storage tanks, increase flow though pipelines, stabilize fuel water-oil emulsions, etc.) (Mulligan, 2005). A wide variety of microorganisms (Pseudomonas aeruginosa, Bacillus sphaericus, Staphylococcus sp, Arthrobacter, etc.) can produce BS using various substrates including sugars, alkanes and wastes such as frying oils, distillery, curd whey byproducts (Elazzazy et al., 2014; Geys et al., 2014; Dubey and Juwarkar, 2001). Nevertheless BS have shown their potential applications, their use is limited because of the lack of cost effective production processes (Reis, et al., 2013). Generally, the BS production costs can be reduced through process optimization of various control factors such as the culture medium composition or/and the growth conditions including limiting nutrients, the trace elements, the addition of inducer, $\mathrm{pH}$, temperature, etc. (Elazzazy et al., 2014). In the context, many studies have been conducted in order to improve the microbial genetics, the production process and the commercial applications of BS (Kuyukina et al., 2001). The nature and the productivity of BS by microorganisms are controlled mainly by the carbon source used during culture. In order to reduce the production cost, the use of cheaper carbon source is needed. In this perspective, many waste materials such as corn oil, molasses, whey and lipids have been used as substrates for BS production (Joshi et al., 2008; Makkar and Cameotra, 1997; Mukherjee et al., 2006; Ramani et al., 2012; Rocha-e-Silva et al., 2014; Santos et al., 2013). However, no studies have examined the feasibility of using tuna processing waste in the formulation of microbial growth media for BS production. In this context, molasses and tuna-by-product based-growth media supplemented with oligoelements were optimized for BS production by $A$. migulanus using mixture design methodology.

\section{MATERIAL AND METHODS}

Tuna by-products sampling, characterisation and treatment

Tuna (Thunnus thynnus) by-product (heads, viscera, skin, some muscle tissue and bones) were collected from fish processing industry located in Sfax region 
(Tunisia). Samples were grinded with a grinder, mixed with water $\left(500 \mathrm{~g} . \mathrm{L}^{-1}\right)$ and heated at $100^{\circ} \mathrm{C}$ for $20 \mathrm{~min}$. After heat pre-treatment, insoluble material was removed by centrifugation (10000 rpm for $30 \mathrm{~min}$ ). The obtained supernatant was stored at $-20^{\circ} \mathrm{C}$ until use. Supernatant was subject to characterisation according to the AOAC methods (AOAC, 1990), water content was quantified by drying samples at $100^{\circ} \mathrm{C}$, lipid by Soxhlet extraction, nitrogen by Kjeldahl procedure, and ash by incineration in a muffle furnace at $550^{\circ} \mathrm{C}$. Protein content was calculated using a rate of $6.25 \%$ nitrogen to protein (AOAC, 1990).

\section{Molasses sampling and characterisation}

Molasses were sampled from the sugar refining industry (Tunisian Society of Sugar Beja, Tunisia) and stored at $4^{\circ} \mathrm{C}$ until use. Sample was subject to chemical characterisation as described in the AOAC methods (AOAC, 1990).

\section{Microbial strain and culture conditions}

A. migulanus NCTC TSA 7092 was used throughout this study. A. migulanus was maintained at $4^{\circ} \mathrm{C}$ on Luria Broth (LB) solid medium (10 g... $\mathrm{L}^{-1}$ tryptone, 5 g. $\mathrm{L}^{-1}$ yeast extract, $10 \mathrm{~g} \mathrm{~L}^{-1} \mathrm{NaCl}$ and $15 \mathrm{g.L} \mathrm{L}^{-1}$ agar, $\mathrm{pH} \mathrm{7.0)}$ and inoculum preparation was conducted in Erlenmeyer flask containing $50 \mathrm{~mL}$ of liquid LB medium (the flask was sterilized at $121^{\circ} \mathrm{C}$ for $20 \mathrm{~min}$ and incubated at $30^{\circ} \mathrm{C}$ overnight on a rotary shaker at $200 \mathrm{rpm}$ )

Microbial growth was studied in media based on molasses solution ( 34.5 g.L $\left.\mathrm{L}^{-1}\right)$, supernatant generated by boiling tuna by-product and oligoelements solution (composed of in g.L ${ }^{-1}: \mathrm{KH}_{2} \mathrm{PO}_{4}, 1 ; \mathrm{K}_{2} \mathrm{HPO}_{4}, 1 ; \mathrm{MgSO}_{4}, 7 \mathrm{H}_{2} \mathrm{O}, 0.2 ; \mathrm{CaCl}_{2}, 2 \mathrm{H}_{2} \mathrm{O}$, 0.02 and $\mathrm{FeCl}_{3}, 6 \mathrm{H}_{2} \mathrm{O}, 0.05$ ). Experiments were conducted in $500 \mathrm{~mL}$ Erlenmeyer flasks each containing $100 \mathrm{~mL}$ of medium. The initial $\mathrm{pH}$ of the medium was adjusted to 7.0 . Then, culture media were sterilised at $121^{\circ} \mathrm{C}$ for $20 \mathrm{~min}$. Flasks were inoculated with $4 \%(\mathrm{v} / \mathrm{v})$ of the inoculum and growth was performed for 72 hours under the same conditions used to prepare the inoculum.

\section{Emulsification index (E24)}

Emulsification assays of the BS were performed using the method described by Cooper and Goldenberg (1987). The emulsification activity of the supernatan was measured by adding $3 \mathrm{~mL}$ petroleum ether to $3 \mathrm{~mL}$ of the culture supernatan in a test tube, vortexing for $2 \mathrm{~min}$, and then leaving it to settle for $24 \mathrm{~h}$. E24 was estimated as the height of the emulsion layer, divided by the total height, multiplied by 100 .

\section{Biosurfactant determination}

BS was extracted from the culture medium after cell removal by centrifugation at $8500 \mathrm{rpm}$ for $10 \mathrm{~min}$ at $4^{\circ} \mathrm{C}$. The supernatant $\mathrm{pH}$ was adjusted to 2.0 with $1.0 \mathrm{~N}$ $\mathrm{HCl}$ solution. Pellet thus precipitated was collected by centrifugation $(8500 \mathrm{rpm}$ for $20 \mathrm{~min}$ at $4^{\circ} \mathrm{C}$ ). The precipitate was then re-dissolved in distilled water and collected by centrifugation $\left(8000 \mathrm{rpm}\right.$ for $45 \mathrm{~min}$ at $4{ }^{\circ} \mathrm{C}$ ). The operation was repeated twice. The yield of isolated BS was expressed in g.L ${ }^{-1}$ (Chander $\boldsymbol{e t}$ al., 2012).

\section{Experimental design and statistical analysis}

The Design-Expert (7.0) Software (Stat-Ease Inc., USA) was used to determine the optimum proportions of culture medium formulation. The mixture components consisted of volume of molasses $\left(X_{I}\right)$, volume of tuna by-product supernatant $\left(X_{2}\right)$ and volume of oligoelements solution $\left(X_{3}\right)$. All components had the same range, between 0 and 1 . Components proportions were expressed as ratios of each compound volume to the mixture ( $\operatorname{sum} X_{1}+X_{2}+X_{3}=1$ ). These three components levels were used to investigate their effect on BS production and E24. The design-expert software generated 15 runs for each culture medium and responses (BS production and E24) were determined experimentally for each one.

The regression models of responses (BS production and E24) were established through second order polynomial equation and were presented as follows (Eq. 1):

$Y=b_{1} X_{1}+b_{2} X_{2}+b_{3} X_{3}+b_{12} X_{1} X_{2}+b_{13} X_{1} X_{3}+b_{23} X_{2} X_{3}+b_{123} X_{1} X_{2} X_{3}(1)$

Where $Y$ is the response (BS production and E24), $X_{1}, X_{2}$ and $X_{3}$ were the levels of variables (molasses, tuna by-product supernatant and oligoelements, respectively), $b_{1}, b_{2}, b_{3}$ were coefficients of linear term and $b_{12}, b_{13}, b_{23}, b_{123}$ were the interaction coefficients.

The statistical and mathematical analyses were evaluated using Design Expert 7. The effects of the three variables were calculated, as well as their possible interactions on the BS and E24. The significance of each variable was evaluated using analysis of variance (ANOVA).

\section{RESULTS AND DISCUSSION}

BS are of considerable commercial interest in various commercial applications in the petroleum, pharmaceuticals, biomedical and food processing industries (Reis et al., 2013). Due to their beneficial properties such as biodegradability, BS were proposed to replace chemical surfactants. However, BS production depends especially on the raw material cost, which represent about $10-30 \%$ of the global production cost (Cameotra and Makkar, 1998). Consequently, the choice of low-cost raw materials for the preparation of the microbial growth media is an important way to ensure the economy of the BS process. Interestingly, many strategies were used for economical BS production using selected bacteria and economic growth media (Fox and Bala, 2000; Makkar and Cameotra, 1999). In this context, a mixture design was applied to determine the optimum conditions for BS productions and to maximize the E24 by A. migulanus growing on media based on molasses supplemented with supernatant generated from boiled tuna by-product and with oligoelements. Molasses is a co-product of refining of sugar beets into sugar. The extensive use of molasses as carbon source is related to its low price compared to other sources, and the presence of several other compounds and vitamins which are valuable for microbial growth (Gaurav et al., 2014). Interestingly, fish by-product, which are an easily available substrates generated in large amount by the Tunisian industries, provide an excellent source for microbial growth media (especially nitrogen and minerals), which can be exploited in producing various high added value metabolites (Ben Rebah and Miled, 2013). The integration of both molasses and tuna-by-product in microbial growth media for BS production, can lower the bioprocess cost and reduce environmental problems associated with agro-waste materials and propose another environmental friendly disposal way.

\section{Raw material composition}

The composition of raw materials (molasses and supernatant generated by boiled tuna processing by-product) was determined (Table 1). There were significan differences $(P<0.05)$ in proteins, lipids, ash and carbohydrates contents between supernatant generated by boiled tuna processing by-product and molasses. Tuna by-product contained the highest protein, lipid and ash contents $(46.41 \pm 2.42$; $5.33 \pm 1.10 \%$ and $41.30 \pm 2.54$ of total dry weight (w/dw), respectively). However, molasses showed the highest levels in carbohydrates $(86.84 \pm 2.51 \%)$. Generally, fish processing by-product contain growth factors offering good potential as culture media for microbial growth (Ben Rebah and Miled, 2013; DehghanNoudeh et al., 2009). In order to enhance the soluble protein fraction and ash contents, various pre-treatment processes (heat treatment, chemical and enzymatic treatment, etc.) have been applied to fish wastes before being used as growth media (Ben Rebah et al., 2008; Huang et al., 2011; Poernomo and Buckle, 2002) As reported by Ben Rebah et al. (2013) applying heat treatment $\left(100^{\circ} \mathrm{C}, 20 \mathrm{~min}\right)$ on fish by-product for microbial growth use, may has numerous advantages (simpler process, reduction of energy requirement, and consequently the cost production). Hence, the heat treatment allows the solubilisation of minerals contained in bones for tuna by-product (Ben Rebah and Miled, 2013; Ben Rebah et al., 2008). Furthermore, high temperature treatment may affect the quality of the boiled product, such as the structure and the solubility of proteins (Ben Rebah and Miled, 2013; Niamnuy, 2002; Poernomo and Buckle, 2002) allowing an enhancement of the alkali-soluble protein fraction as reported while treating shrimp by-product (Niamnuy et al., 2008). Although, fish processing waste may be considered as potential nitrogen source and salts, in some cases the presence of lipids in this waste may inhibit the microbial growth as reported by Ben Rebah et al. (2013).

Table 1 Chemical composition of molasses and tuna by-product; means of three replicates (\% dry weight).

\begin{tabular}{lcccc}
\hline & Proteins & Lipids & Ash & Carbohydrates** \\
\hline Molasses & $2.27 \pm 0.52$ & $1.26 \pm 0.36$ & $9.63 \pm 1.62$ & $86.84 \pm 2.51$ \\
\hline $\begin{array}{l}\text { Tuna by- } \\
\text { product } \\
\text { supernatant* }\end{array}$ & $46.41 \pm 2.42$ & $5.33 \pm 1.10$ & $41.30 \pm 2.54$ & $6.96 \pm 2.02$ \\
\hline
\end{tabular}

supernatant

"Supernatants obtained after heat treatment $\left(100^{\circ} \mathrm{C} ; 20 \mathrm{~min}\right)$ of raw materials

${ }^{*}$ Carbohydrates were calculated by the difference $[100 \%-($ proteins $+\quad$ lipids + ash $)]$.

\section{Experimental design data and analysis of the models}

The optimal conditions for BS production were predicted using the optimization function of the Design Expert software. To improve the economic competitiveness of microbial BS production, tuna-by-product and molasses based-growth media were optimized. Oligoelements solution was also added to the growth media. In this study, BS production and E24 were maximized by mixture proportions given in Table 2 .

The response data (E24 and BS production) in Table 2 were converted into two polynomial equations with three independent variables. Consequently, the polynomial models describing the correlation between responses and variables were (Eq. 2-3):

$Y_{E 24(\text { in } \%)}=49.12 X_{I}+62.55 X_{2}+67.10 X_{3}$; with adjusted $\mathrm{R}^{2}=0.545$ (Eq. 2) $Y_{B S \text { (in } g / l)}=3.22 X_{1}+0.91 X_{2}+1.93 X_{3}-5.40 X_{1} X_{2}-9.93 X_{1} X_{3}-3.91 X_{2} X_{3}+$ $36.92 X_{1} X_{2} X_{3}$; with adjusted $\mathrm{R}^{2}=0.816$ (Eq. 3 ) 
Where $Y_{E 24}$ and $Y_{B S}$ are the predicted responses of E24 and biosurfectant production, respectively. $X_{1}, X_{2}$ and $X_{3}$ are the proportions of molasses, tuna by-

Table 2 Mixture design matrix with the observed and predicted values.

\begin{tabular}{cccccccc}
\hline & \multicolumn{3}{c}{ Experimental Condition } & \multicolumn{2}{c}{ E24 $(\%)$} & \multicolumn{2}{c}{ Biosurfactant $(\mathrm{g} / \mathrm{l})$} \\
\hline Run & $\begin{array}{c}\text { Molasses } \\
\left(X_{I}\right)\end{array}$ & $\begin{array}{c}\text { Tuna by-product } \\
\text { supernatant }\left(X_{2}\right)\end{array}$ & $\begin{array}{c}\text { Oligoelement } \\
\text { solution }\left(X_{3}\right)\end{array}$ & Observed & Predicted & Observed & Predicted \\
\hline 1 & 0.95 & 0.05 & 0 & 50 & 49.8 & 3.2 & 2.8 \\
\hline 2 & 0.05 & 0.95 & 0 & 60 & 61.9 & 0.6 & 0.8 \\
\hline 3 & 0.05 & 0.05 & 0.9 & 70 & 66.0 & 1.7 & 1.3 \\
\hline 4 & 0.5 & 0.5 & 0 & 51 & 55.8 & 0.6 & 0.7 \\
\hline 5 & 0.5 & 0.05 & 0.45 & 64.6 & 57.9 & 0.7 & 0.1 \\
\hline 6 & 0.05 & 0.5 & 0.45 & 64 & 63.9 & 0.7 & 0.2 \\
\hline 7 & 0.35 & 0.35 & 0.3 & 60 & 59.2 & 1.5 & 1.1 \\
\hline 8 & 0.65 & 0.2 & 0.15 & 54 & 54.5 & 1.1 & 0.8 \\
\hline 9 & 0.2 & 0.65 & 0.15 & 65 & 60.6 & 1.2 & 0.1 \\
\hline 10 & 0.2 & 0.2 & 0.6 & 53 & 62.6 & 0.6 & 0.1 \\
\hline 11 & 0.05 & 0.05 & 0.9 & 62 & 66.0 & 1.2 & 1.3 \\
\hline 12 & 0.05 & 0.5 & 0.45 & 68 & 63.9 & 0.6 & 0.2 \\
\hline 13 & 0.95 & 0.05 & 0 & 48 & 49.8 & 2.6 & 2.8 \\
\hline 14 & 0.5 & 0.5 & 0 & 59 & 55.8 & 0.8 & 0.7 \\
\hline 15 & 0.05 & 0.95 & 0 & 61 & 61.9 & 0.8 & 0.8 \\
\hline
\end{tabular}

ANOVA was also performed (Table 3 ). The associated $p$-value was used to estimate whether $F$-value was large enough to indicate statistical significance. A $p$-value below 0.05 indicates that the model was statistically significant. As indicated in table 3 for both E24 and BS production, linear mixture components were significant model terms. The values of $R^{2}$, a measurement for fitness of the regressed Eq. 2 and Eq. 3 were 0.61 and 0.89, respectively. These results indicated that the experimental data were in a good agreement with predicted values.

Table 3 ANOVA and regression analysis of the model for E24 and biosurfactant production.

\begin{tabular}{|c|c|c|c|c|c|c|}
\hline Source & $\begin{array}{c}\text { Sum of } \\
\text { Squares }\end{array}$ & $\begin{array}{c}\text { Degrees of } \\
\text { freedom }\end{array}$ & Mean Square & F-value & p-value & \\
\hline \multicolumn{7}{|l|}{ E24 } \\
\hline Model & 387.524 & 2 & 193.762 & 9.397 & 0.0035 & significant* \\
\hline Linear Mixture & 387.524 & 2 & 193.762 & 9.397 & 0.0035 & \\
\hline Residual & 247.425 & 12 & 20.619 & & & \\
\hline Lack of Fit & 172.925 & 7 & 24.704 & 1.658 & 0.2988 & not significant \\
\hline Pure Error & 74.500 & 5 & 14.900 & & & \\
\hline Cor Total & 634.949 & 14 & & & & \\
\hline \multicolumn{7}{|l|}{ R-Squared $=0.610$} \\
\hline \multicolumn{7}{|c|}{ Biosurfactant production } \\
\hline Model & 7.669 & 6 & 1.278 & 11.364 & 0.0015 & significant* \\
\hline Linear Mixture & 4.268 & 2 & 2.134 & 18.970 & 0.0009 & \\
\hline $\mathrm{X}_{1} \mathrm{X}_{2}$ & 1.603 & 1 & 1.603 & 14.250 & 0.0054 & \\
\hline $\mathrm{X}_{1} \mathrm{X}_{3}$ & 2.224 & 1 & 2.224 & 19.768 & 0.0022 & \\
\hline $\mathrm{X}_{2} \mathrm{X}_{3}$ & 0.234 & 1 & 0.234 & 2.081 & 0.1871 & \\
\hline Residual & 0.876 & 1 & 0.876 & 7.789 & 0.0235 & \\
\hline Lack of Fit & 0.900 & 8 & 0.112 & & & \\
\hline Pure Error & 0.550 & 3 & 0.183 & 2.618 & 0.1631 & not significant \\
\hline Cor Total & 0.350 & 5 & 0.070 & & & \\
\hline R-Squared $=0.895$ & & & & & & \\
\hline
\end{tabular}

The regression coefficients for all terms in optimized models were analyzed. In the case of E24 (Eq.2), the effect of $X_{3}$ (67.10) was more important than that of $X_{2}(62.55)$ and $X_{l}$ (49.12). However, for BS production (Eq.3), the influence of $X_{i}$ (3.22) was more important than that of $X_{2}(0.91)$ and $X_{3}(1.93)$, indicating that the molasses proportion $\left(X_{I}\right)$ was the main factor controlling the higher BS production.

Positive coefficients for a three-component blend mean that the three components were complementary. This is the case of BS production when combing molasses with tuna byproduct supernatant and oligoelements (Eq.3). Also, the fact that two-component blends have negative coefficients, means that the two components were non-complementary (Eq.3). This was the case of the interactions of $X_{1} X_{2}, X_{1} X_{3}$ and $X_{2} X_{3}$.

The best way to predict the relationships between responses and the growth medium compositions is to analyze the contours diagrams or the three dimensional surface plot generated from the estimated models. The contours 
diagrams (A) and response surface (B) of E24 and BS production were depicted in figure. 1 and 2 , respectively.
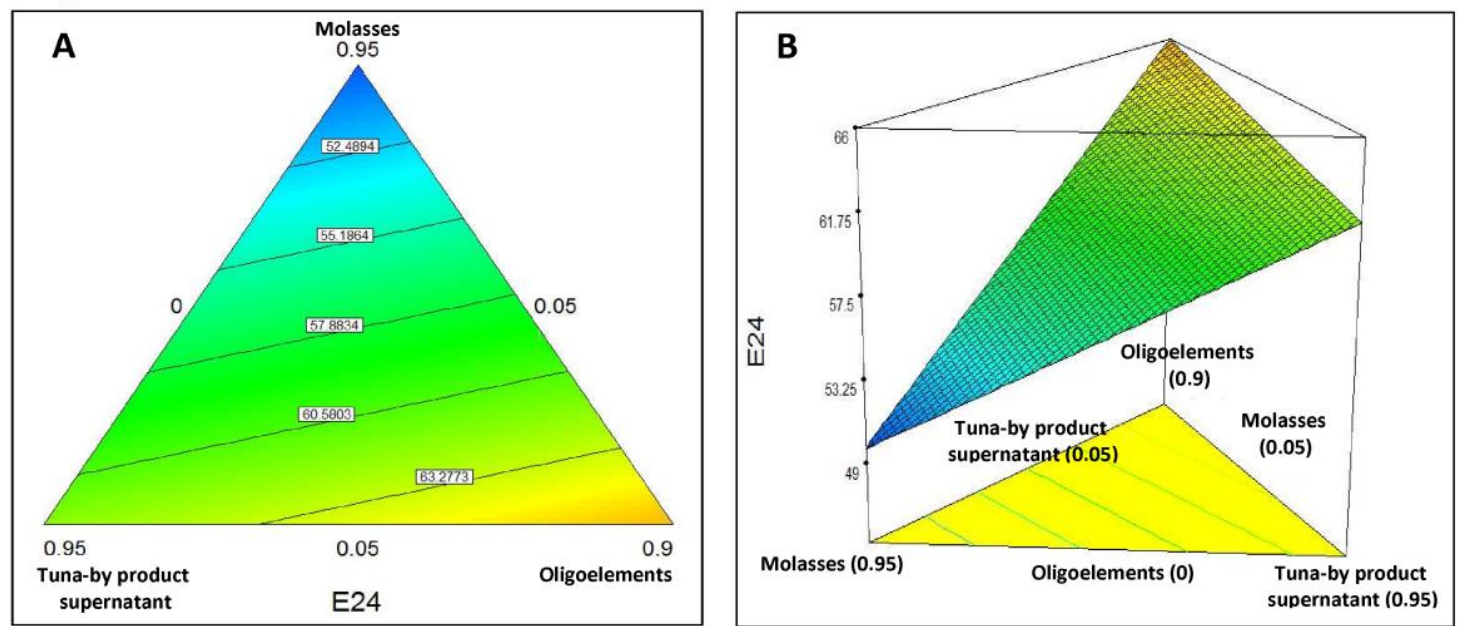

Figure 1 Contour diagrams (A) and response surface (B) for E24 resulted of growing A. migulanus as a function of the added molasses, tuna-by product supernatant and oligoelements.
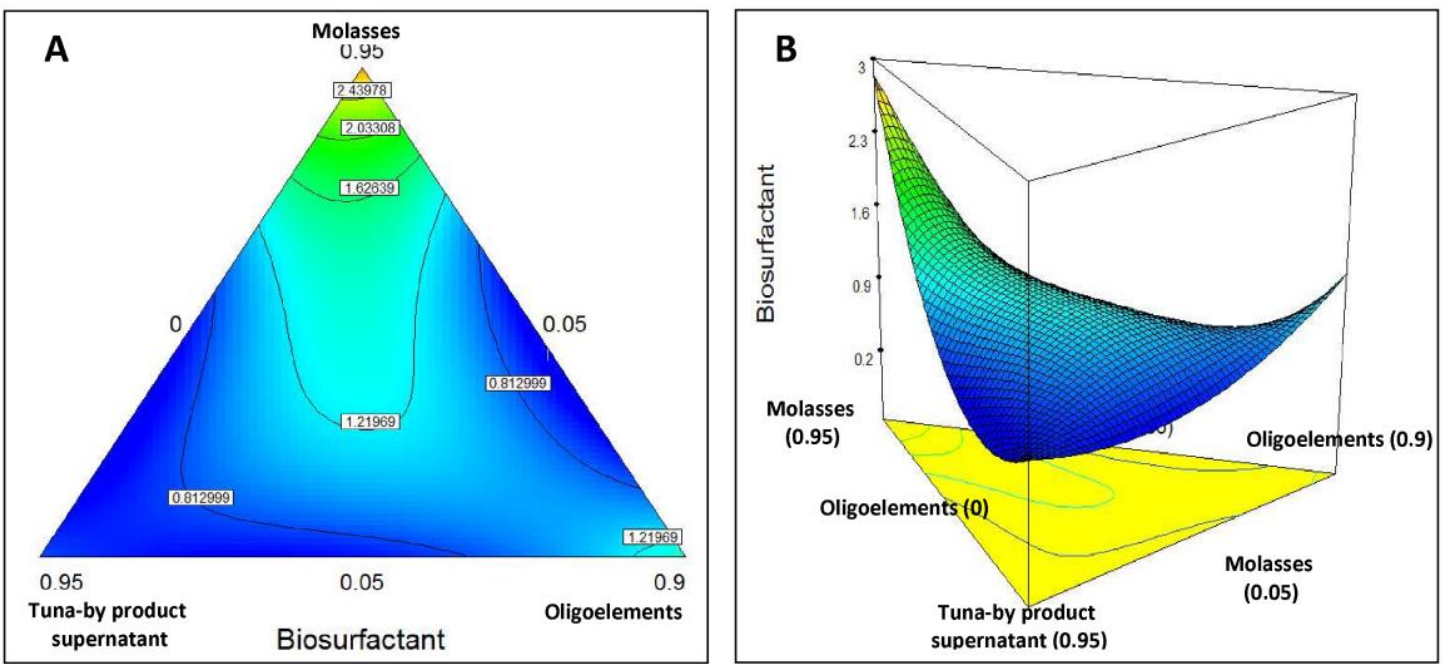

Figure 2 Contour diagrams (A) and response surface (B) for biosurfactant produced by A. migulanus as a function of the added molasses, tuna-by-product supernatant and oligoelements.

E24 decreased gradually with the added amount of molasses. Similarly, adding tuna-by-product supernatant reduced E24, but with lesser extent while compared to molasses effect. Interestingly, the addition of oligoelements (up to 90\%) to the medium increased E24 and values remained between 50 and $70 \%$. The variation of the E24 may be explained by the variation of the BS concentration in the culture medium or/and by the nature of BS morphology. According to Ron et al. (2002) low molecular weight BS effectively reduce the interfacial tensions, while the high molar mass polymers such as lipopeptides are less effective in reducing the interfacial tensions. Moreover, the E24 was evaluated using the culture supernatant and its composition may have an effect on the E24 value. Hence, the production of secondary metabolite and the remained nutrient form the growth medium could interfere with emulsion formation (Bonilla et al., 2005) Moreover, the morphology of BS can be significantly affected by $\mathrm{pH}$ variations, which may control the surface tension and dispersion rate (Shin et al., 2004). The ionic strength or salinity of the medium could also affect the process (Abouseoud et al., 2010).

BS production decreased progressively with the enhancement of tuna-by-product supernatant rate in the culture medium. This may be explained by the inhibition of the BS production which is related to the microbial growth. Lipids content in tuna-by-product may affect the bacterial growth and consequently the BS production as reported for other microorganisms cultivated in fish waste-based media (Vazquez, 2004). In contrast, it was reported that agroindustrial waste with high content of carbohydrates, or lipids meet the requirement for use as substrate for BS production (Makkar and Cameotra, 1999).

Generally, results indicated that molasses and tuna-by-product contain nutrients necessary to sustain the growth of A. migulanus and consequently the BS production. The positive effect of molasses may be explained by its higher carbohydrates and amino-acids contents. Slight addition of tuna-by-product supernatant may increase the BS production. However, an over addition of tuna supernatant decreases both BS production and E24 this may be related to the unbalanced nutrients concentrations. The beneficial use of molasses as a carbon source supplemented with yeast extract, or other nitrogen source and some metal ions for BS production has been reported by many studies (Dubey and Juwarkar, 2001; Patel and Desai, 1997). However, according to Joshi et al. (2008), the only use of molasses without addition of nitrogen source, or metal supplements allow acceptable yield of BS production by Bacillus strains. It seems that BS production depends on the used species (having different nutrient requirements) and on molasses characteristics which vary depending on its origin and this may affect the microbial growth and the BS production. In this perspective, for example in the study of $P$. Aeruginosa strain (Dubey and Juwarkar, 2001), it was reported that an industrial waste based media should have optimum carbon, nitrogen, phosphorus and iron concentrations with $\mathrm{C} / \mathrm{N}$, $\mathrm{C} / \mathrm{P}$ and $\mathrm{C} / \mathrm{Fe}$ ratios suitable for maximum production of $\mathrm{BS}$. Therefore, it is very important to determine in molasses and in fish by-product the specific factors, the nature of nitrogen-containing compounds such as the amino acid composition and the small-size peptides that might be vital factors for A. migulanus growth and BS production.

\section{Optimization of mixing proportion for responses and validation of the model}

The optimal conditions for E24 and BS production were predicted using the optimization function of the Design Expert software. The formulation of an economic and competitive medium and maximization of both emulsification index and biosurfactnat production were satisfied by mixture proportions given in Table 4. These solutions provide E24 of $61.88 \pm 4.541 \%$ and $2.4 \pm 0.335 \mathrm{~g} / 1$ of BS. Experiments were conducted under optimal conditions in order to assess the validity of regression models (Table 4). The result demonstrated that the experimental data were in good agreement with the predicted values, confirming the validity and the adequacy of the predicted models. Interestingly, in optimized media, no additional oligoelements were required. However, the addition of oligoelements considerably stimulated cell growth and BS production (Reis et 
al., 2004). Indeed, in the present study, tuna-by-product and molasses were used as based media to the growth of $A$. migulanus. These two media contained an appreciable level of ash $(41.30 \pm 2.54 \%$ and $9.63 \pm 1.62 \%$, respectively) which was generally correlated to the salt content. Therefore, oligoelements is provided by molasses or/and tuna-by-product media.

Table 4 Solutions for optimal conditions as generated by the Design Expert Software

\begin{tabular}{ccccccc}
\hline \multicolumn{7}{c}{ Experimental Condition } \\
\hline \multicolumn{3}{c}{ Nutrient source $(\mathbf{m L})$} & \multicolumn{4}{c}{ Response } \\
\hline $\begin{array}{c}\text { Molasses } \\
\left(\mathrm{X}_{1}\right)\end{array}$ & $\begin{array}{c}\text { Tuna by-product } \\
\text { supernatant }\left(\mathrm{X}_{2}\right)\end{array}$ & $\begin{array}{c}\text { Oligoelement } \\
\text { solution }\left(\mathrm{X}_{3}\right)\end{array}$ & $\begin{array}{c}\text { Observed } \\
\text { value }\end{array}$ & $\begin{array}{c}\text { Predicted } \\
\text { Value }\end{array}$ & $\begin{array}{c}\text { Observed } \\
\text { value }\end{array}$ & $\begin{array}{c}\text { Predicted } \\
\text { value }\end{array}$ \\
\hline 95 & 5 & 0 & $2.95 \pm 0.353$ & $2.4 \pm 0.335$ & - & - \\
\hline 5 & 95 & 0 & - & - & $62 \pm 1.553$ & $61.88 \pm 4.541$ \\
\hline
\end{tabular}

\section{CONCLUSION}

In this study we show that molasses and tuna-by-product, non conventiona substrates (agro-industrial by-product), can be used efficiently for BS production by A. migulanus. The BS production process using these materials is a relatively inexpensive and economic process, which can be easily adapted for various environmental applications. Moreover, we demonstrated that the mixture design methodology can be used to determine the optimum medium mixtures based on molasses and supernatant generated by boiling tuna-by-product, allowing to maximize BS production and E24. These studies will give insights into the potential of using industrial wastes. However, more investigations are needed to determine effects of others factors (temperature, $\mathrm{pH}$, oxygenation, etc.) related to the bioprocess. Additionally the recent availability of the genome sequences of the strain used in this study and another strain of A. migulanus (Alenezi et al. 2015a, b) will help identify genes that control biosynthesis of BS and the regulatory mechanisms underlying their biosynthesis.

\section{REFERENCES}

A.O.A.C. (1990). Official Methods of Analysis, 15th ed. Washington, DC: Association of Official Analytical Chemists.

Abouseoud, M., Yataghene A., Amrane, A. \& Maachi, R. (2010). Production of a biosurfactant by Pseudimonas fluorescens-solublilizing and wetting capacity. Chem. Eng. Trans, 20, 291-296. http://dx.doi.org/10.3303/CET1020049

Alenezi, F.N., Weitz, H.J., Belbahri L., Ben Rebah, H., Luptakova, L., Jaspars, M., \& Woodward, S. 2015. Draft Genome Sequence of Aneurinibacillus migulanus Strain Nagano. Genome Announc, 3(2), e00232-15. http://dx.doi.org/10.1128/genomeA.00232-15

Alenezi, F.N., Weitz, H.J., Belbahri, L., Nidhal, J., Luptakova, L., Jaspars, M. \& Woodward, S. (2015). Draft Genome Sequence of Aneurinibacillus migulanus NCTC 7096. Genome Announc, 3(2), e00234-15. http://dx.doi.org/10.1128/genomeA.00234-15

Ashby, R.D., McAloon, A.J., Solaiman, D.K., Yee, W.C. \& Reed, M. (2013). A process model for approximating the production costs of the fermentative synthesis of sophorolipids. J. Surfactants Deterg., 16(5), 683-691. http://dx.doi.org/10.1007/s11743-013-1466-0

Babu, P.S., Vaidya, A.N., Bai, A.S., Kapur, R. \& Juwarkar, A. (1996). Kinetics of biosurfactant production by Pseudomonas aeruginosa strain BS2 from industrial wastes. Biotechnol. Lett., 18, 263-268 http://dx.doi.org/10.1007/BF00142942

Banat, I.M., Franzetti, A., Gandolfi, I., Bestetti, G., Martinotti, M.G., Fracchia, L., Smyth, T.J. \& Marchant, R. (2010). Microbial biosurfactants production, applications and future potential. Appl. Microbiol. Biotechnol., 87, 427-444 http://dx.doi.org/10.1007/s00253-010-2589-0

Ben Rebah, F., Frikha, F., Belbahri, L., Miled, N. \& Gargouri, Y. (2008). Culture of $S$. xylosus in fish processing by-product-based media for lipase production. Lett. Appl. Microbiol., 47, 549-554. http://dx.doi.org/10.1111/j.1472 765X.2008.02465.X

Ben Rebah, F. \& Miled, N. (2013). Fish processing by-products for microbia enzyme production: A review. Biotechnol. 3, 255-265. http://dx.doi.org/10.1007/s13205-012-0099-8

Bonilla, M., Olivaro, C., Corona, M., Vazquez, A. \& Soubes, M. (2005). Production and characterization of a new bioemulsifier from Pseudomonas putida ML2. J. Appl. Microbiol., 98, 456-508. http://dx.doi.org/10.1111/j.13652672.2004.02480.x

Cameotra, S.S, \& Makkar, R.S. (2010). Biosurfactant enhanced bioremediation of hydrophobic pollutants. Pure Appl. Chem., 82(1), 97 116. http://dx.doi.org/10.1351/PAC-CON-09-02-10

Cameotra, S.S. \& Makkar, R.S. (1998). Synthesis of biosurfactants in extreme conditions. Appl. Microbiol. Biotechnol., 50, 520-529. http://dx.doi.org/10.1007/s002530051329

Chayabutra, C., Wu, J. \& Ju, L.K. (2001). Rhamnolipid production by Pseudomonas aeruginosa under denitrification: Effects of limiting nutrients and carbon substrates. Biotechnol. Bioeng., 72, 25-33. http://dx.doi.org/10.1002/1097-0290(20010105)72:1<25::AID-BIT4>3.0.CO;2-J Chander, C.R., Lohitnath, T., Mukesh Kumar, D.J. \& Kalaichelvan, P.T. (2012) Production and characterization of biosurfactant from Bacillus subtilis MTCC441 and its evaluation to use as bioemulsifier for food bio-preservative. Adv. Appl. Sci. Res., 3(3), 1827-1831.

Chen, S.Y., Wei, Y.H. \& Chnd, J.S. (2007). Repeated pH-stat fed-batch fermentation for rhamnolipid production with indigenous Pseudomonas aeruginosa S2. Appl. Microbiol. Biotechnol., 76, 67-74. http://dx.doi.org/10.1007/s00253-007-0980-2

Cooper, D.G. \& Goldenberg, B.G. (1987). Surface-active agents from two bacillus species. Appl. Environ. Microbiol., 53, 224-229. http://dx.doi.org/00992240/87/020224-06\$02.00/0

Dehghan-Noudeh, G., Moshafi, M. H., Behravan, E., Torkzadeh, S. \& Afzadi, M.A. (2009). Screening three strains of Pseudomonas aeruginosa: Prediction of biosurfactant-producer strain. Am. J. Appl. Sci., 6, 1453-1457. http://dx.doi.org/10.3844/ajassp.2009.1453.1457

Deleu, M. \& Paquot, M. (2004). From renewable vegetables resources to microorganisms: New trends in surfactants. C. R. Chim., 7, 641-646. http://dx.doi.org/10.1016/j.crci.2004.04.002

Dubey, K., Juwarkar, A., 2001. Distillery and curd whey wastes as viable alternative sources for biosurfactant production. World J. Microbiol. Biotechnol. 17, 61-69. http://dx.doi.org/10.1023/A:1016606509385

Elazzazy, A.M., Abdelmoneim, T.S. \& Almaghrabi, O.A. (2015). Isolation and characterization of biosurfactant production under extreme environmental conditions by alkali-halo-thermophilic bacteria from Saudi Arabia. Saudi J. Biol. Sci., 22 (4), 466-475. http://dx.doi.org/10.1016/j.sjbs.2014.11.018

Fox, S., Bala, G., (2000). Production of surfactant from Bacillus subtilis ATCC 21332 using potato substrates. Biores. Technol. 75, 235-240. http://dx.doi.org/10.1016/S0960-8524(00)00059-6

Gaurav, K., Srivastava, R., Sharma, J.G., Singh, R. \& Singh, V. (2014). Molasses Based Growth and Lipid Production by Chlorella pyrenoidosa: A Potential Feedstock for Biodiesel. Int. J. Green Energy, (just-accepted) http://dx.doi.org/10.1080/15435075.2014.966268

Geys, R., Soetaert, W. \& Van-Bogaert, I. (2014). Biotechnological opportunities in biosurfactant production. Curr. Op. Biotechnol., 30, 66-72. http://dx.doi.org/10.1016/j.copbio.2014.06.002

Huang, L., Zhang, B., Gao, B. \& Sun, G. (2011). Application of fishmeal wastewater as a potential low-cost medium for lipid production by Lipomyces starkeyi HL. Env. Technol., 32, 1975-1981. http://dx.doi.org/10.1080/09593330.2011.562551

Joshi, S., Bharucha, C., Jha, S., Yadav, S., Nerurkar, A. \& Desai, A.J. (2008) Biosurfactant production using molasses and whey under thermophilic conditions. Biores. Technol. http://dx.doi.org/10.1016/j.biortech.2006.12.010

Kuyukina, M.S., Ivshina, I.B., Philip, J.C., Christofi, N., Dunbar, S.A.E. \& Ritchkova, M.I. (2001). Recovery of Rhodococcus biosurfactants using methyl tertiary-butyl ether extraction. J. Microbiol. Methods., 46, 149-156. http://dx.doi.org/10.1016/S0167-7012(01)00259-7

Makkar, R.S. \& Cameotra, S.C. (1999). Biosurfactant production by microorganisms on unconventional carbon sources. J. Surfactants Deterg., 2, 237-241. http://dx.doi.org/10.1007/s11743-999-0078-3

Makkar, R.S. \&Cameotra, S.S. (1997). Utilization of molasses for biosurfactant production by two Bacillus strains at thermophilic conditions. J. Am. Oil Chem. Soc., 74, 887-889. http://dx.doi.org/10.1007/s11746-997-0233-7

Makkar, R.S. \& Cameotra, S.S. (2002). An update on the use of unconventional substrates for biosurfactant production and their new applications. Appl. Microbiol. Biotechnol., 58, 428-434. http://dx.doi.org/10.1007/s00253-001-0924-

Mukherjee, S., Das, P. \& Sen, R. (2006). Towards commercial production of $\begin{array}{llll}\text { microbial surfactan. } & \text { Trends } \quad \text { Biotechnol., } & \text { 24, }\end{array}$ 515. http://dx.doi.org/10.1016/j.tibtech.2006.09.005

Mulligan, C.N. (2005). Environnemental applications for biosurfactants. Environ. Poll., 133, 183-198. http://dx.doi.org/10.1016/j.envpol.2004.06.009

Muthusamy, K., Gopalakrishnan, S., Ravi, T.K. \& Sivachidambaram, P. (2008) Biosurfactants: properties, commercial production and application. Curr. Sci., 94 736-747.

Niamnuy, C., Devahastin, S. \& Soponronnarit, S. (2007). Quality changes of shrimp during boiling in salt solution. J. Food Sci., 72, 289-297. http://dx.doi.org/10.1111/j.1750-3841.2007.00349.x

Niamnuy, C., Devahastin, S. \& Soponronnarit, S., (2008). Changes in protein compositions and $\mathrm{S}$. their effects on physical changes of shrimp during boiling in 
salt solution. Food Chem., 108, 165-175. http://dx.doi.org/ 10.1016/j.foodchem.2007.10.058

Patel, R.M. \& Desai, A.J. (1997). Biosurfactant production by Pseudomonas aeruginosa GS3 from molasses. Lett. Appl. Microbiol., 25, 91-94. http://dx.doi.org/10.1046/j.1472-765X.1997.00172.x

Poernomo, A. \& Buckle, K.A. (2002). Crude peptones from cowtail ray (Trygon sephen) viscera as microbial growth media. World J. Microbiol. Biotechnol., 18, 333-340. http://dx.doi.org/10.1023/A:1015208519709

Ramani, K., Jain, S.C., Mandal, A.B. \& Sekaran, G. (2012). Microbial induced lipoprotein biosurfactant from slaughterhouse lipid waste and its application to the removal of metal ions from aqueous solution. Colloids Surf. B Biointerfaces. 97, 254-263. http://dx.doi.org/10.1016/j.colsurfb.2012.03.022

Reis, F.A., Sérvulo, E.F.C. \& De França, F.P. (2004). Lipopeptide surfactant production by Bacillus subtilis grown on low-cost raw materials. Appl. Biochem. Biotechnol., 115(1-3), 899-912. http://dx.doi.org/0273-2289/04/115/0899-0912

Reis, R., Pacheco, G. J., Pereira, A. G., \& Freire, D. M. G. (2013) Biosurfactants: production and applications. New York: InTech http://dx.doi.org/10.5772/56144

Rocha-e-Silva, N.M.P., Rufino, R.D., Luna, J.M., Santos, V.A. \& Sarubbo, L.A. (2014). Screening of Pseudomonas species for biosurfactant production using low-cost substrates. Biocatal. Agric. Biotechnol., 3, 132-139. http://dx.doi.org/10.1016/j.bcab.2013.09.005

Rodrigues, L.R., Teixeira, J.A. \& Oliveira, R. (2006). Low-cost fermentative medium for biosurfactant production by probiotic bacteria. Biochem. Eng., 32 135-142. http://dx.doi.org/10.1016/S0958-1669(02)00316-6

Ron, E. Z. \& Rosenberg, E. (2002). Biosurfactants and oil bioremediation. Curr. Opinion Biotechnol., 13, 249-252. http://dx.doi.org/10.1016/S09581669(02)00316-6

Rosen, M.J. \& Kunjappu, J.T. (2012). Surfactants and interfacial phenomena John Wiley \& Sons.

Santos, D.K.F., Rufino, R.D., Luna, J.M., Santos, V.A., Salgueiro, A.A. \& Sarubbo, L.A. (2013). Synthesis and evaluation of biosurfactant produced by Candida lipolytica using animal fat and corn steep liquor. J. Petrol. Sci. Eng., 105, 43-50. http://dx.doi.org/10.1016/j.petrol.2013.03.028

Shin, K.H., Kim, K.W. \& Seargen, E.A. (2004). Combined effects of pH and biosurfactant addition on solubilization and biodegradation of phenanthrene. Appl. Microbiol. Biotechnol., 65, 336-343. http://dx.doi.org/10.1007/s00253004-1561-2

Soberón-Chávez G. \& Maier R.M. (2011). Biosurfactants: a General Overview. In Biosurfactants (Soberón-Chávez, G., ed.), Springer-Verlag, Berlin, Germany, pp. 1-11.

Tapaneyasin, R., Devahastin, S. \& Tansakul, A. (2005). Drying methods and quality of shrimp dried in a jet-spouted bed dryer. J. Food Process. Eng., 28, 35 52. http://dx.doi.org/ 10.1111/j.1745-4530.2005.00394.x

Van Hamme, J.D, Singh, A, \& Ward, O.P. (2006). Physiological aspects. Part 1 in a series of papers devoted to surfactants in microbiology and biotechnology. Biotechnol. Adv., 24(6), 604-620. http://dx.doi.org/10.1016/j.biotechadv.2006.08.001

Vazquez, J.A. Gonzalez, M.P. \& Murado, M.A. (2004). A new marine mediumUse of different fish peptones and comparative study of the growth of selected species of marine bacteria. Enz. Microbiol. Technol., 35, 385-392. http://dx.doi.org/10.1016/j.enzmictec.2004.02.007

Volchenko, N.N., Karasev, S.G., Nimchenko, D.V. \& Karaseva, E.V. (2007) Cell hydrophobicity as a criterion of selection of bacterial producers of $\begin{array}{lll}\text { biosurfactants. } & \text { Microbiol., } & \text { 16, }\end{array}$ http://dx.doi.org/10.1134/s0026261707010158

Yu, H. \& Huang, G.H. (2011). Isolation and characterization of biosurfactant and bioemulsifier producing bacteria from petroleum contaminated sites in Western Canada. Soil and Sediment Contam., 20 (3), 274-288 http://dx.doi.org/10.1080/15320383.2011.560981 